The Development of Individual Physically Aggressive Behaviors from Infancy to Toddlerhood

\author{
Michael F. Lorber \\ New York University
}

Tamara Del Vecchio

St. John's University

Amy M. Smith Slep

New York University

In Press, Developmental Psychology.

CAmerican Psychological Association, 2017. This paper is not the copy of record and may not exactly replicate the authoritative document published in the APA journal. Please do not copy or cite without author's permission. The final article is available, upon publication, at: http://dx.doi.org/10.1037/dev0000450

The research in this report was supported by Centers for Disease Control and Prevention Grant B1U49CE001246-01PR. 


\begin{abstract}
In the present investigation, we studied the development of six physically aggressive behaviors in infancy and toddlerhood, posing three questions (1) How do the prevalences of individual physically aggressive behaviors change from 8, 15, and 24 months? (2) Are there groups of children who show distinctive patterns in the way individual physically aggressive behaviors develop over time? (3) What are the behavioral pathways leading from 8- to 24month acts of physical aggression? Mothers and fathers $(N=272)$ from a moderately at-risk population reported on their children's physical aggression at each time point. The results revealed the commonality of physical aggression at all ages studied and the diverging developmental patterns of individual behaviors. Some physically aggressive behaviors became less common (e.g., hair pulling), while others became more common (e.g., hitting), with age. Roughly $42 \%$ of the children exhibited an increased propensity, relative to their peers, to aggress at all ages. Kicking, biting, hair pulling, and pinching/scratching at 8 months were the first steps on behavioral pathways leading to physical aggression at 24 months. These pathways principally suggested heterotypic continuity in physical aggression.
\end{abstract}

Keywords: physical aggression, infancy, toddlerhood, longitudinal, development. 
The Development of Individual Physically Aggressive Behaviors from Infancy to Toddlerhood

Nearly all children are thought to exhibit at least some form of physical aggression in the first few years of life (Hay, 2005; Tremblay \& Nagin, 2005). Physical aggression is known to be particularly common in toddlerhood (Hay, 2005; Tremblay \& Nagin, 2005; Nærde, Ogden, Janson, \& Daae Zachrisson, 2014) - exemplified by the so called "terrible twos." Yet a growing body of research has shown that these behaviors are common prior to age 2 (Alink et al., 2006; Nærde et al., 2014), having been reported in children as young as 6 to 8 months of age (Hay et al., 2010; Lorber, Del Vecchio, \& Slep, 2015). The present report is a continuation of this new wave of research in which we probe the development of physical aggression between 8 and 24 months. Tremblay and Côté (2005) argued that "[t]aking a developmental perspective means, first, to understand the development (change over time) of the phenomenon we are trying to predict, and second, to describe the causal chain of events over time that explain the development" (p. 449). In this spirit, we investigated which aggressive behaviors develop when, and in whom, and identified behavioral pathways leading from physical aggression at 8 months to physical aggression at 24 months.

At the outset, it is important to clarify our approach to the phenomenon of aggression in the early months of life. As pointed out by several writers (Hay, 2016; Lorber, Del Vecchio, \& Slep, 2014; Tremblay, 2000), there is disagreement about whether it is appropriate to refer any behavior as "aggressive" when performed by infants. Some theorists prefer a definition of aggression that requires intent to harm and/or a kind of means-end calculation about what the impact or instrumental value of the act is (e.g., Dodge, Coie, \& Lynam, 2006; Maccoby, 1980). Such cognitive capacities come on-line later than the earliest instances of kicking, pushing, hitting, biting, pinching, scratching and hair pulling, the onset of which we review below. In contrast to such views, we prefer a topographical definition of 
physical aggression that does not require intent and means-end calculations (e.g., Tremblay, 2000). Such cognitive attainments likely diversify the function of physical aggression over developmental time, however they are not prerequisites to performing the behaviors we describe as physically aggressive (e.g., hitting and kicking). As we will review, these behaviors do in fact happen in infancy, exhibit longitudinal stability, and occupy a recognizable position in the nomological network of constructs related to aggression at later ages. We believe this evidence to be a sufficient justification of the topographical approach to the earliest forms of aggression.

\section{The Normative Development of Physical Aggression}

Following Sroufe and colleagues' unity of development principal, the normative changes in physical aggression that may be expected in the first two years of life are most usefully contextualized in the child's social, emotional, physical, and cognitive growth - the overall development of the person (Sroufe, Egeland, Carlson, and Collins, 2005). A host of developmental attainments converge to make physical aggression more and more likely in this period. In humans and other primates, aggressive behaviors are thought to be evolutionarily preserved, instinctive reactions to the aversive behavior of others (Tremblay \& Nagin, 2005; Tremblay \& Côté, 2005). Unsurprisingly then, early physical aggression is closely linked to anger (Lorber et al., 2015). Anger comes on-line in the first six months (Lewis, 2008) and exhibits population level growth thereafter (Braungart-Rieker, HillSoderlund, \& Karrass, 2010; Lemerise \& Dodge, 2008). Infants' rapid development of goal directed behavior, and the ability to recognize it in others, during this same period (Tomasello, Carpenter, Call, Behne, \& Moll, 2005) likely also play a role in supporting the growth of anger, and in turn, aggression. Infants come to have their own goals (e.g., reaching for a desired toy) and recognize when others are blocking them. Paired with increasingly independent ambulation (World Health Organization Multicentre Growth Reference Study 
Group, 2006), the cognitive, emotional, and social changes in infancy and toddlerhood lead to increasingly frequent conflicts with caregivers (Biringen, Emde, Campos, \& Appelbaum, 1995; Campos et al., 2000; Klimes-Dougan \& Kopp, 1999), providing increasing opportunities for aggressive behaviors (Tremblay, 2000). Moreover, increasing muscle strength and motor coordination may also make physical aggression more possible and certainly provide opportunities for it to become more targeted with age (e.g., Adolph \& Robinson, 2015).

Empirical literature on the development of physical aggression prior to 24 months is limited. However, the first instances of physical aggression appear to occur as early as the second half of the first year. Based on mothers' retrospective reports of their physically aggressive 17-month-old infants, pushing, hitting, and kicking would be expected to exhibit very low prevalences $(\leq 5 \%)$ prior to 11 months (Tremblay et al. 1999). These observations are largely consistent with the results of observational studies of Canadian and British infants (Hay, Hurst, Waters, \& Chadwick, 2011; Restoin et al., 1985 cited in Tremblay \& Nagin, 2005). Yet two recent studies in which parent-reported physical aggression was measured age-concurrently in children between 6 and 11 months old tell a different story. In a normative British sample, Hay et al. (2010) reported hitting (3 to 8\%), biting (9 to $12 \%$ ), and hair pulling (51 to $71 \%$ ) in many 6-month old infants. In a normative study of Norwegian children Nærde et al. (2014) found that on average 36\% of infants as young as 8 months were reported to have hit their parents.

Slightly more data are available on physical aggression at 12 months. In a normative Dutch study beginning at 12 months, parents reported that about one-half of their children exhibited physical aggression (Alink et al., 2006). The Norwegian parents of Nærde et al. (2014) reported that 15 to $43 \%$ of their 12 -month-old children exhibited hitting parents, hitting siblings, or pushing. The British parents or grandparents of in the Hay et al. (2010) 
sample reported that 55 to $96 \%$ of their children exhibited hair pulling, hitting, or biting at 12 months (Hay, personal communication; January 6, 2016). Finally, 31\% of the British children of Hay et al. (2011) were observed to be aggressive in peer interactions at 12 months.

Physical aggression has been shown to become sharply more common between 12 and 24 months in parent-report studies. For example, in the studies of Alink et al. (2006) and Nærde et al. (2014), parents reported that about one-third to one-half of their 12-month olds exhibited physical aggression, with this number increasing to approximately $75 \%$ by 2 to 3 years of age. The results of three small observational studies, however, did not suggest significant changes in the prevalence of aggression between 12 and 24 months (Brownlee \& Bakeman, 1981; Dunn \& Munn, 1985; Hay et al., 2011). We note, however, that increases in the level or frequency of aggression between 12 and 24 months were apparent in the results of Brownlee and Bakeman (1981), Eckerman, Whatley, and Kutz (1975), Hay et al. (2011), Restoin et al. (1985; cited in Tremblay \& Nagin, 2005), Tremblay et al. (2004), and Alink et al. (2006), suggesting that aggression can intensify without becoming more prevalent.

Individual physically aggressive behaviors are also closely related to one another. Children who, for example, hit more frequently also tend to kick, bite, and pull others' hair more frequently. The findings of at least three studies of physical aggression covering the 8to 24-month age range suggest that individual physically aggressive behaviors reflect a single underlying factor (Alink et al., 2006; Lorber, Del Vecchio, \& Slep, 2014; Nærde et al., 2014). Yet such interrelations among different physically aggressive behaviors do not necessarily suggest that they all move in tandem across developmental time. Rather, the topography of physical aggression likely changes with maturation (Tremblay \& Côté, 2005). As suggested at the beginning of this section, aggressive behaviors may become more common due to increased physical strength and motor abilities, cognitive sophistication, capacity for anger, independent ambulation, and conflict with caregivers. However, it is possible that other 
behaviors become less frequent over time. For example, hair pulling, pinching, and scratching may be unskilled grasping behaviors that are more frequent earlier in infancy but fade over time due motor and physical gains (Adolph \& Berger, 2006). These potentially competing maturational forces suggest the need to disaggregate the physical aggression construct to more fully understand its development.

\section{Individual Differences in Physical Aggression}

Although aggression in the first two years of life is clearly normative, individual differences among children are reasonably stable and occupy a recognizable position in the nomological network of constructs related to aggression and other externalizing behaviors at later ages. For example, Lorber, Del Vecchio, and Slep (2015) reported a .40 stability of physical aggression from 8 to 24 months and Alink et al. (2006) reported a .49 stability of physical aggression from 12 to 24 months. Further, in Lorber et al. (2014) and Van Zeijl et al. (2006), physical aggression in the 8- to 15-month age range was associated with parent report measures of difficult temperament, distress to limitations, activity level, and nonverbal defiance, as well as with observational measures of physical struggle and distress vocalizations. Moreover, a composite of physical aggression and anger at 6 months of age was associated with observed peer-directed physical force at one year of age (Hay et al., 2010) and parent-reported aggression at age three (Hay et al., 2014). Taken together these studies suggest that the emergence of meaningful variation in aggressive behavior can be detected in the first and second year of life.

A principle concern with physical aggression in the first two years of life is that for some children it may be the leading edge of a pattern of persistently elevated physical aggression or externalizing behavior problems more broadly. After its peak in toddlerhood, as young children develop higher-order cognitive abilities and self-regulatory capacity, physically aggressive behavior generally declines throughout childhood (Côté, Vaillancourt, 
LeBlanc, Nagin, \& Tremblay, 2006; Côté, Vaillancourt, Barker, Nagin, \& Tremblay, 2007). However, some children appear to not "outgrow" their toddler-era aggression. In normative samples, rates of persistently elevated aggression from toddlerhood through middle childhood have ranged from approximately 3\% to 18\% (Côté et al., 2006; Côté et al., 2007; NICHD Early Child Care Research Network \& Arsenio, 2004; Tremblay et al., 2004). Such "early starters" are at increased risk for a broad range of externalizing, internalizing, and social problems in later childhood (e.g., Campbell, Spieker, Burchinal, Poe, \& NICHD Early Child Care Research Network, 2006). Accordingly, although most toddlers initially aggress and eventually decrease or cease their use of aggression, understanding the early variability in patterns of aggressive behaviors exhibited by infants and toddlers could help to identify targets for prevention efforts timed to a developmental period in which child behaviors might be most malleable.

\section{The Present Study}

In the present study we examined the development of individual physically aggressive behaviors at 8, 15, and 24 months: kicking, pushing, hitting, biting, pinching/scratching, and hair pulling. To better understand topographical changes, we explored the development of each of six physically aggressive behaviors individually rather than in aggregate. The investigation was arranged around three broad questions.

\section{Question 1: How do the prevalences of specific physically aggressive behaviors}

change from 8 to 15 to 24 months? In light of the relatively limited literature on aggression in infancy and early toddlerhood, we thought it important to learn about how the prevalences of aggressive behaviors shift with age. As reviewed above, many normative developmental attainments and the indications from some, although clearly not all, prior research suggest that increases are to be expected. Despite this rationale for predicting the increasing commonality of physical aggression between 8 and 24 months of age, there are 
countervailing maturational forces (e.g., motor development) and conflicting evidence, as we also reviewed above. Thus, we cautiously predicted increasing prevalences in each physically aggressive behavior.

\section{Question 2: Are there groups of children who show distinctive patterns in the} way individual physically aggressive behaviors develop over time? As reviewed above, a trajectory marked by persistently high levels of physical aggression has been identified in children as young as 17 to 24 months old and physical aggression exhibits significant relative or rank order stability from as early as 8 to 12 months of age. These findings raise the question of whether the developmental trajectory marked by persistently elevated early onset aggression begins in the first year. If so, this group of infants might have consistently high prevalences of multiple individual aggressive behaviors as the variety of aggressive acts contributes greatly to the mean score across aggressive acts. The presence of an early onset aggressive group in the first two years of life is far from guaranteed however, as the stability results of two studies (Alink et al., 2006; Lorber et al., 2015) suggest that the majority of variance in physical aggression at age 2 is not predicted by 8- and 12-month aggression. Moreover, early onset children may differ with respect to the forms of aggression they exhibit at different ages and such proclivities may remain stable or change over time. To our knowledge, there are no extant data that speak to these questions, thus we do not offer specific hypotheses.

Question 3: What are the behavioral pathways leading from 8- to 24-month acts of physical aggression? As previously noted, physical aggression exhibits significant relative or rank-order stability from the first to second year of life. Yet the way that a child "earns a high aggression score" may differ over time as a function of maturation - so called heterotypic continuity (i.e., stability in the construct but change in its morphology; Patterson, 1993; Shaw \& Bell, 1993; Sroufe, 2009). For example, an 8-month-old infant may earn a 
high aggression score primarily through pinching and hair pulling, behaviors that may be reflexive reflections of an immature motor system; that same child may earn a high aggression score at age 2 by hitting and kicking, behaviors that are more goal directed, targeted, coordinated, and executed with greater appreciation of their consequences.

Stability in aggression is by mathematical necessity driven most strongly by the behaviors that are more variable at each age. Behaviors that are rare at any given age contribute proportionately little to overall variation in physical aggression at that age. Consider an example in which hitting is rare and hair pulling is common at age 1, with this pattern reversed at age 2 - a pattern that seems possible given the results of Hay et al. (2010) and Alink (personal communication; November 21, 2015). In this case, if there is significant stability in the underlying physical aggression construct between ages 1 and 2, that stability is likely to be more strongly driven by the association of hair pulling at age 1 with hitting at age 2 than by the homotypic or topographic continuity in those behaviors (i.e., hair pulling with hair pulling; hitting with hitting). Given the likely shifts in the commonality of individual physically aggressive behaviors at different ages, such as decreasing prevalences of hair pulling and increasing prevalences of hitting, continuity is likely to be of the heterotypic variety.

On the other hand, social processes can create homotypic continuity in specific behaviors. For example, an infant may initially pull her mother's hair as the exploratory behavior of immature motor and muscular systems; one that would likely fade as she matures. Yet if the hair pulling is positively reinforced as a behavior that intermittently or reliably gains the mother's attention, it is likely to be repeated in the future (Patterson, 2002). Thus, the behavior pathways a child traverses between infant and toddlerhood may be a function of both homotypic and heterotypic continuity in the aggression construct. 
Given how little is known about the development of individual aggressive behaviors in the first two years, we adopted an exploratory approach to identifying the pathways of physically aggressive behaviors at 8,15 , and 24 months of age. We reasoned that there would be continuity in aggression, but that it might be either heterotypic (e.g., hair pulling $\rightarrow$ biting $\rightarrow$ hitting), homotypic (e.g., kicking $\rightarrow$ kicking $\rightarrow$ kicking), or both.

\section{Method}

\section{Participants}

The participants included in the present report were 272 opposite sex couples with a child ( $\sim 51 \%$ girls) who had been recruited from two hospital maternity wards in the suburbs of a large American city. They were a subset of a sample of 378 couples recruited for a randomized controlled trial evaluating the effects of an intervention designed to prevent intimate partner violence. To be included in the parent study, couples must have been English speaking ( $87 \%$ qualified) married or cohabiting parents of a neonate (90\% qualified) with $\geq 1$

parent under age 30 (60\% qualified) and who reported at least one of four common manifestations of intimate psychological aggression (shouting/yelling, insults/swearing at, stomping out of the house in anger, and doing things to spite the partner) (89\% qualified), but no physical aggression that resulted in injuries, pain, or fear ( $98 \%$ qualified).

The study parents $[M$ age $=26.72(S D=3.80)$ for mothers and $29.23(S D=5.24)$ for fathers] were couples (64\% married) whose median annual family income was $\$ 56,000$ (interquartile range $=\$ 30,000$ to $\$ 94,000)$. The majority did not have college degrees $(59.9 \%$ of mothers and $66.5 \%$ of fathers). Mothers described themselves as Black or Caribbean (14.4\%), Latina (17.8\%), White (61.1\%), Asian (4.4\%), or mixed race (2.2\%). Fathers described themselves as Black or Caribbean (17.4\%), Latino (24.8\%), White (52.2\%), Asian (2.6\%), Native American (1.1\%), mixed race (1.5\%), or Pacific Islander (0.4\%). 
Demographic comparisons to US American Community Survey data are provided in Table S1 of the on-line supplement to this article.

The measures included in the present report came from home visits at $8(n=215), 15$ $(n=184)$, and $24(n=232)$ months of child age. Accordingly, the couples included were those that completed at least one of these assessments; $n=146$ completed all three waves, $n=$ 67 completed two waves, and $n=59$ completed one wave of assessment. As reported in Lorber et al. (2015), couples who dropped out were more likely to be unmarried and have a father with a high school education/GED or less.

\section{Procedure}

Home visits occurred within three months of child birth $(M=1.14, S D=.81)$, and at 8 $(M=8.44, S D=1.33), 15(M=15.26, S D=1.04)$, and $24(M=24.78, S D=2.22)$ months of child age. At each assessment, the mothers and fathers independently completed a questionnaire measuring child aggression, as well as several other measures that are not of focus in the present report. At the end of the initial assessment, couples were randomly assigned to receive the modified Couple CARE for Parents intervention or waitlisted until child age 24 months. The 7 -session intervention was completed prior to the 8 -month assessment. The intervention is not a focus of the present manuscript and is described in Heyman et al. (2017) and Halford, Petch, and Creedy (2010). As reported in Lorber et al. (2014, 2015), it had no impact on physical aggression or other externalizing behaviors at any age in the present sample.

\section{Measures}

Parents completed the Infant Externalizing Questionnaire (IEQ; Lorber et al., 2014) at each wave of assessment. They were instructed to complete the IEQ to reflect their view of their child's behavior, “even if other people might not agree.” The IEQ's 6-item Physical Aggression subscale items are "kicks people," "pushes people," "hits or smacks people," 
"bites people," “pulls people's hair,” and "pinches or scratches people.” IEQ items are purely descriptive, reflecting the topography of behaviors. The aggression items were influenced by those of existing measures of early childhood aggression (Achenbach \& Rescorla, 2000; Tremblay et al., 1999). We carefully considered the developmental relevance of each item to ensure that they were behaviorally feasible in infants as young as 8 months of age.

Qualifications were made where developmentally necessary (e.g., biting, not including nursing, and even if the baby has no teeth). Each item is rated as $0=$ not at all true, $1=$ somewhat or sometimes true, and $2=v e r y$ true or often true; the time frame is "now or within the past 2 months.” To create dual-informant scores for analysis, each item was dichotomized as behavior present/absent (1/0) if it had been endorsed by either parent.

The IEQ's psychometrics are reported in Lorber et al. (2014), who studied the same sample. Lorber et al. reported significant mean internal consistency (Cronbach's $\alpha=.75$ ), interparental agreement $(r=.45)$ and longitudinal stabilities $(r=.50)$ of the Physical Aggression scale across the 8, 15, and 24 month assessments.

\section{Results}

All analyses were conducted using Mplus version 7.2 (Muthén \& Muthén, 19982012), using full information maximum likelihood estimation to handle missingness (22.9\%), and keeping the analysis $N$ at a constant 272.

\section{Research Questions 1 and 2}

Patterns of physical aggression across the entire sample (Question 1) and in subsets of the sample (Question 2) could each be evaluated with a unifying statistical framework: latent class analysis (LCA). LCA is used to identify classes of individuals with distinct behavior patterns that are not directly observable, thus it was appropriate for Question 2. However, all LCA models begin with the estimation of a 1-class model against which the fit of models with more classes is compared. The 1-class model takes advantage of the entire covariance 
matrix to yield probability estimates (i.e., prevalences) and corresponding confidence intervals for each behavior; these probabilities were the focus of Question 1.

A series of LCA models were evaluated using all physically aggressive behaviors at 8 , 15, and 24 months as class indicators. To identify the number of latent classes, additional LCAs were estimated for models with up to 4 classes. The Bayesian Information Criterion (BIC) - a model fit index that penalizes for model complexity - was computed for each model. Lower values indicate better fit. The BIC value decreased between the 1-class (4749.97) and 2-class (4379.54) models, but then increased for the 3-class (4381.02) and 4class models (4391.24). Moreover, a significant Lo-Mendell-Rubin test (Nylund, Asparouhov, \& Muthén, 2007) indicated that the 2-class model better fit the data than did the 1-class model $(p<.001)$. The average latent class probabilities for each child's most likely latent class membership based on the 2-class model were .94 (Class 1) and .95 (Class 2); entropy was .80. Thus, the 2-class model fit the data well and was considered the final model. In Table 1 and Figure 1 the probabilities of each aggressive behavior at 8, 15, and 24 months are presented for the full sample, corresponding to the 1-class model and Question 1, as well as Classes $1(42.21 \%$ of the sample) and $2(57.79 \%$ of the sample) from the 2 -class model, corresponding to Question 2.

One-class model (Question 1). Each physically aggressive behavior had a significantly non-zero prevalence at each age, as their $95 \%$ confidence intervals did not include zero. At 8 months, the prevalence of each behavior ranged from approximately $13 \%$ to $73 \%$. Hair pulling was by far the most prevalent behavior, followed by pinching/scratching, hitting, biting, kicking, and pushing. By 15 months, the rank order had shifted somewhat, with hitting the most prevalent behavior, followed by hair pulling, biting, pinching/scratching, pushing, and kicking; prevalences ranged from about $18 \%$ to $62 \%$. By 24 months, the relative commonality of the behaviors had once again shifted somewhat. 
Hitting remained the most common behavior, followed by pushing, biting, pinching/scratching, kicking, and hair pulling; prevalences ranged from about $31 \%$ to $67 \%$. Descriptively, the prevalences of each behavior measured at 8 months were modestly negatively correlated with their prevalences at 24 months $(r=-.24)$; i.e., the relative commonality of the behaviors largely reorganized between 8 and 24 months.

After relatively little change in the prevalence of kicking between 8 and 15 months [ 4 percentage point (PP) decrease], a 13.3 PP increase was observed between 15 and 24 months. Pushing became steadily more common with age, increasing by 18.0 PP between 8 and 15 months, and 18.4 PP between 15 and 24 months. Hitting initially increased greatly (by 23.4 PP between 8 and 15 months), with little evidence of change between 15 and 24 months (4.8 PP increase). Biting increased by 16.0 PP between 8 and 15 months, then decreasing between 15 and 24 months (-14.3 PP). Hair pulling became steadily less common with age, decreasing by $22.6 \mathrm{PP}$ between 8 and 15 months and 19.6 PP between 15 and 24 months. There was little change in the prevalence of pinching/scratching between 8 and 15 months (-0.2 PP), followed by a larger decrease between 15 and 24 months (-12.1 PP).

The near ubiquity of physically aggressive behaviors. Over the course of the study, parents reported that $91.2 \%(95 \%$ CI: $87.8 \%$ to $94.5 \%)$ of the children exhibited at least one of the six physically aggressive behaviors. The prevalences were $79.1 \%(95 \% \mathrm{CI}: 76.3 \%$ to $84.5 \%$ ) at 8 months, $80.4 \%$ (95\% CI: $74.7 \%$ to $86.2 \%)$ at 15 months, and $79.7 \%$ (95\% CI: $74.6 \%$ to $84.9 \%$ ) at 24 months.

Two-class model (Question 2). Classes 1 (42.21\% of the sample) and 2 (57.79\%) exhibited generally similar patterns of each physically aggressive behavior over time (Figure 1). However, Class 1 had significantly higher prevalences of most of the behaviors at all ages and its developmental trends tended to be amplified. The behaviors whose prevalences did not significantly differ between classes were hair pulling and hitting at 8 months, kicking at 
15 months, and hitting and hair pulling at 24 months. Odds ratios (OR) comparing the Class 1 vs. 2 prevalences of each behavior at each age were computed. The $p$-values (corrected for multiple testing) of these comparisons are reported in the far right column of Table 1. Benjamini and Hochburg's (1995) false discovery rate adjustment (FDR) was applied to the six $p$-values at each age, corresponding to the six behaviors being compared between classes at each age. The corresponding ORs ranged from 4.17 to $23.24(M=9.62)$, all but two of which were significant: hit at 15 months and hair pull at 24 months. Compared to the OR, however, the relative risk or risk ratio (RR) is a generally more easily interpretable metric as it compares probabilities rather than odds (Davies, Crombie, \& Tavakoli, 1998). Thus RRs were also calculated for each comparison $\left(\mathrm{RR}=\operatorname{prob}_{\text {Class } 1} 1 /\right.$ prob lass $\left._{2}\right)$ and ranged from 1.50 to $8.94(M=3.79)$; compared to Class 2 prevalences, physically aggressive behaviors were on average more than 3.5 times as prevalent in Class 1 . The physically aggressive behaviors' prevalences relative to one another were highly similar between Class 1 and Class 2 at each wave of assessment; $r \mathrm{~s}=.95$ (8 months), .92 (15 months), and .93 (24 months).

\section{Research Question 3}

To examine the behavioral pathways leading from 8- to 24-month physically aggressive behaviors, the longitudinal associations among the behaviors were first screened in a 2-stage process. In the first stage, we looked for significant associations between 8month (potential predictors) and 24-month (potential outcomes) behaviors. In the second stage, we looked for 15-month behaviors (potential mediators) that were associated with each pair of 8- and 24-month behaviors from the first stage. Combinations of variables that passed each screening stage - those that suggested potential mediated pathways - were then advanced to analyses in which the indirect effects were statistically evaluated.

A saturated $(d f=0)$ covariance matrix among all physically aggressive behaviors at each age was estimated using the weighted least squares means and variance adjusted 
(WLSMV) estimator. WLSMV is commonly used for modeling the associations among categorical variables in structural equation modeling (Beauducel \& Herzberg, 2006). The longitudinal associations, which are in the probit metric (equivalent to the tetrachoric correlation), among the behaviors are summarized in Table 2. Their confidence intervals and $p$-values are reported in Table S2 of the on-line supplement to this article. An FDR adjustment was applied to $p$-values for the association of a given behavior at one wave of assessment (e.g., 8 mos) with each of the six behaviors at a future wave (e.g., 15 mos). Based on significant associations of (a) a given 8-month predictor and 24-month outcome, as well as significant associations of a potential 15-month mediator with the aforementioned significantly associated (b) 8-month and (c) 24-month behaviors, 16 candidate pathways from 8- to 24-month physically aggressive behaviors were identified.

The indirect effect for each candidate pathway was statistically evaluated in separate path models. In each model the candidate mediator was regressed on the predictor ( $\alpha$ path); the 24-month outcome was simultaneously regressed on the candidate 15 -month mediator $(\beta$ path) and 8-month predictor. The so-called pure natural indirect effect (PNIE) of each compound pathway $(\alpha \beta)$ was computed. PNIE is a newly implemented "causal mediation analysis" method in Mplus that is capable of handling dichotomous mediators and outcomes (Muthén \& Asparouhov, 2015). The PNIE is a more generalized case of the typical $\alpha \beta$ test of mediation (MacKinnon, Lockwood, Hoffman, West, \& Sheets, 2002) that is considered superior because it imposes weaker assumptions. The typical $\alpha \beta$ test assumes linearity among the variables that may not be satisfied (e.g., there may be a predictor $\times$ mediator interaction; Imani, Keele, \& Tingley, 2010).

For each mediated pathway evaluated, the PNIE, effect size, and estimates for the $\alpha$ and $\beta$ paths (in the OR metric) are presented in Table 3. Bias corrected bootstrapped $95 \%$ CIs (based on 10,000 replicates) are reported for each estimate. Following the logic of the $R^{2}$ in 
multiple regression, effect size of the indirect effect was expressed as the ratio of the indirect to total effect - the $\mathrm{P}_{\mathrm{M}}$ measure (Preacher \& Kelley, 2011). We describe the significant indirect effects here. Kicking at 8 mos led to biting at 24 mos along two pathways, via hair pulling and pinching/scratching at 15 months. Kicking at 8 months led to hair pulling at 24 months along three pathways, via kicking, hair pulling, and pinching/scratching at 15 months. Biting at 8 months led to hitting at 24 months along four pathways, via kicking, pushing, hitting, and pinching/scratching at 15 months. Hair pulling at 8 mos led to kicking at 24 mos via hair pulling at 15 mos and to hair pulling at 24 mos via hair pulling at 15 mos. Pinching/scratching at 8 months led to kicking at 24 months via biting at 15 months. Pinching/scratching at 8 months further led to biting at 24 months along 2 pathways, via biting and pinching/scratching at 15 months. Pinching/scratching at 8 months also led to hair pulling at 24 months along two pathways, via biting and pinching/scratching at 15 months.

\section{Discussion}

Consistent with Hay's (2005) suggestion that physical aggression is a nearly ubiquitous feature of early human development, approximately $91 \%$ of parents in the present investigation reported that their children had kicked, pushed, hit or smacked, bitten, pinched or scratched people, or pulled people's hair at 8, 15, and 24 months of child age. However, the prevalences varied markedly by behavior and age and were distinctly elevated in a group of about $42 \%$ of the study children. Several pathways among aggressive behaviors could be traced from 8 to 24 months.

\section{Change Between 8 and 24 Months}

Based on the unity of development principal and prior research described in the Introduction, we cautiously predicted increases in rates of each physically aggressive act with age. Most maturational factors would point toward increasing rates of physical aggression (e.g., increasing cognitive sophistication and anger in the infancy-toddlerhood period). 
However, given the present findings, that explanation clearly does not apply to all physically aggressive behaviors. Alternative maturational forces may explain why some physically aggressive behaviors in fact become less common with age.

At each assessment, approximately $80 \%$ of parents reported that their infants or toddlers had aggressed. However, the prevalences of individual physically aggressive behaviors reported at each age shifted considerably. Between 8 and 24 months, there was a significant "reshuffling of the deck." The most, least, and intermediately common behaviors at 8 months were generally not the most, least, and intermediately common behaviors, respectively, at 24 months. To illustrate, at 8 months, hair pulling was far and away the most common behavior, exhibited by more than 7 in 10 children; hitting was exhibited by roughly 4 in 10 children. However, by 24 months, the prevalence of hair pulling had decreased considerably to 3 in 10 children and hitting became the most common behavior, exhibited by nearly 7 in 10 children.

Only hitting and pushing followed the tentatively predicted pattern of increasing prevalences of physically aggressive behaviors with age. The prevalence of kicking changed relatively little between 8 and 15 months, but accelerated between 15 and 24 months. The prevalences of hair pulling and pinching/scratching decreased with age. Finally, the prevalence of biting increased between 8 and 15 months but decreased between 15 and 24 months. Integrating the present study's and prior studies' findings as reviewed in the Introduction to this paper, aggressive behaviors may not universally become more common in the first two years of life.

Why might some aggressive behaviors become more common while others become less so in the first two years of life? Perhaps hair pulling, pinching, scratching, and biting are exploratory behaviors that are common earlier in infancy due to motor and physical immaturity but decrease throughout toddlerhood due the maturation of these systems (Adolph 
$\&$ Berger, 2006). Moreover, prior to achieving independent locomotion - the mean age at which infants first walk alone is 12 months (World Health Organization Multicentre Growth Reference Study Group, 2006) - infants are likely more often held and thus have more plentiful opportunities to pull caregivers' hair, pinch, scratch, and bite than at later, more independent and mobile ages. By contrast, hitting, pushing, and kicking may become more common partly as a function of increased physical strength and motor abilities, cognitive sophistication, capacity for anger, independent ambulation, and conflict with caregivers, which may operate in concert to facilitate increases in physically aggressive behaviors. This pattern of increases in some behaviors and decreases in other behaviors may reflect the development of "aggressive competence" described by Hay (2005; p. 125): the ability to deploy aggression effectively in conflictual encounters. Simply stated, aggressive behaviors that flourish may be the ones that "work best."

Clearly, the above explanations must be recognized as conjecture at this point. Our study lacked measures of explanatory factors beyond age (e.g., motor abilities; amount of close contact with caregivers; capacity for intentionality) for the changing prevalences of physically aggressive behaviors we found. Scientific understanding of aggression in the first two years of life is itself in an early phase of development. Prior to the present study, the field had not - at least on record - considered the possibility that some aggressive behaviors become more common and some less so in the 8- to 24-month age range. Adopting the unity of development perspective, but acknowledging uncertainty due to competing maturational forces and the paucity of prior work in this area, we began with a tentative notion that prevalences might broadly increase with age based on several aspects of normative development. The data, however, suggested otherwise. In line with the reciprocal interplay of theory and findings in the cycle of science, our findings suggest several potential avenues for 
theoretical refinement and future hypothesis testing, particularly if they prove to be replicable.

\section{Distinct Developmental Patterns}

We found two distinct developmental patterns of physical aggression - they differed primarily in the prevalence of aggressive acts at each age studied. Approximately $42 \%$ of study children were on average 3.8 times more likely than the remaining $58 \%$ of children to exhibit each aggressive behavior. Despite the differences in prevalences of aggression, change across the 8-, 15-, and 24-month assessments was similar in the two groups of children. Moreover, the most, least, and intermediately common behaviors in one group tended to be the most, least, and intermediately common behaviors in the other group.

Colloquially, the well-known "terrible twos" - or "terrible ones" as coined by Van Zeijl et al. (2006) - are not as terrible for the larger group of children. The present sample was moderately at-risk for child physical aggression because their parents were only included in the study if they reported psychological interparental aggression and at least one parent was below age 30. Aggression tends to run in families via environmental and genetic mechanisms (Moffitt, 2005) and family violence (a risk factor for infant/toddler aggression; Lorber et al., 2015) is modestly inversely associated with age in adult samples (e.g., Slep \& O’Leary, 2007; O’Leary, Slep, \& O’Leary, 2007). Accordingly, the present sample provided ample opportunity to observe and juxtapose both atypical and normative development of aggression by increasing the presence of maladaptation (Masten, 2011). Yet even in this moderately at-risk sample, the majority of the children were more disinclined than inclined to exhibit each individual aggressive behavior at each age, with 8-month hair pulling the sole exception. We expect that this group (Class 2) would represent an even greater proportion of the children in a population-representative sample. 
Roughly 4 in 10 study children exhibited an elevated propensity to aggress (Class 1). In contrast, in normative samples, prevalences of persistently elevated aggression from toddlerhood through middle childhood have ranged from approximately 3\% to 18\% (Côté et al., 2006; Côté et al., 2007; NICHD Early Child Care Research Network \& Arsenio, 2004; Tremblay et al., 2004). When considering a broader pattern of behaviors including aggression alongside anger, defiance, and angry/irritable affect (i.e., conduct problems), prevalences of persistently elevated problem behavior at these ages are at the lower end of this range (e.g., 5.6\% in Lorber \& Slep, 2015), even in at-risk samples (e.g., 6.7\% in Shaw, Lacourse, \& Nagin, 2005). It is this much smaller group of children that is thought to be on the clinically significant early onset persistent antisocial behavior trajectory (Moffitt, 1993). We suspect that children on the early onset persistent aggressive and antisocial behavior trajectories identified in prior research are a subset of children in the elevated aggression group we identified; that a sizable percentage of these children may eventually behave more like their normative peers sometime after age 2 . Future research will be required to evaluate this prediction and to identify factors that determine which developmental pattern of aggression they will eventually exhibit.

We did not find evidence of specialization in particular aggressive behaviors. For example, there were not "biters," "hitters," or "kickers." Instead there were children who exhibited greater or lesser propensities to aggress. This cohesion among aggressive behaviors is consistent with the factor analytic findings reported in the present sample (Lorber et al., 2014), as well as Nærde et al. (2014); each reported that aggressive behaviors reflected a single underlying construct. Yet, although kicking, pushing, hitting or smacking, biting, pinching/scratching, and hair pulling may reflect a single latent factor, the present findings suggest that these behaviors exhibit different developmental patterns, some increasing (e.g., hitting) and some decreasing (e.g., hair pulling) in prevalence between 8 and 24 months. 


\section{Behavioral Pathways to Age 2 Aggression}

Kicking, biting, hair pulling, and pinching/scratching at 8 months were not "flashes in the pan" with little consequence for future adaptation. They were the first steps on pathways leading to kicking, biting, hair pulling, and hitting at 24 months. There was homotypic continuity in one behavior, with 8-month hair pulling leading to 24-month hair pulling via 15-month hair pulling. Yet in the other significant 8- to 24-month associations, a given behavior at 8 months was associated with a different behavior at 24 months, and sometimes via a third behavior at 15 months. To illustrate, pinching/scratching at 8 months was associated with (a) kicking at 24 months via biting at 15 months, (b) biting at 24 months via biting and pinching/scratching at 15 months, and (c) hair pulling at 24 months via biting and pinching/scratching at 15 months. What these findings appear to reflect is heterotypic continuity - stability in the underlying aggression construct, with less literal equivalence in the form of aggressive behaviors.

\section{Clues About the Meaning of Physical Aggression}

Considering the present and past findings alongside normative developmental changes in the infancy-toddlerhood period offers clues about the meaning of physically aggressive behaviors in this period. We now know that physically aggressive behaviors are common in the 6- to 12-month age range (Hay et al., 2010; Nærde et al., 2014; present article). We know that some aggressive behaviors become less prevalent with age, while others become more prevalent with age as the infant becomes a toddler (present article). We know that they cluster together both in person-centered analyses (i.e., latent class analysis; present article) and variable-centered analyses (i.e., factor analysis; Alink et al., 2006; Lorber et al., 2014; Nærde et al., 2014). We know that they have continuity over time (Alink et al., 2006; Lorber et al., 2015) and that this continuity is primarily heterotypic (present article). We also know that physical aggression in this period is concurrently and prospectively related to several other 
constructs in the nomological network of aggression (e.g., defiance, distress to limitations, activity level, harsh parenting, interparental conflict; Lorber et al., 2014; Lorber et al., 2015).

The above findings jointly suggest that physical aggression in infants is a socially meaningful, consequential behavior, despite infants' relative immaturity. These findings are notable in light of some theorists' arguments that aggression requires intentionality and means-end calculations (Dodge, Coie, \& Lynam, 2006; Maccoby, 1980). Even though infants are not likely capable of intentional physical aggression and making means-end calculations about the impact of their behaviors, the accumulating evidence suggests that physically aggressive behaviors are nonetheless meaningful as early as 6-8 months of age. Such evidence reinforces the developmental appropriateness of the topographic approach to defining and studying physical aggression in infancy. Although they are not integral to our definition of physical aggression, cognitive attainments such as intentionality and means-end calculations, however, likely diversify the function of physical aggression over developmental time. These intriguing possibilities are worthy of future research.

\section{Strengths and Limitations}

The present parent report methodology has well known weaknesses, such as the subjectivity of rating criteria. We compensated for these weaknesses by combining mothers' and fathers' independent reports to determine the presence of physical aggression at each age. Multi-informant measures are psychometrically superior to single-informant measures in the assessment of child behavior (Johnston \& Murray, 2003; Kerr, Lunkenheimer, \& Olson, 2007). Moreover, the prevalences of aggressive behaviors in the present study are fairly consistent with those in other studies based on parent report (e.g., hair pulling being particularly common in the first year of life, as in Hay et al., 2010). Yet, on the whole, the prevalences of aggressive behaviors reported by parents in such studies have tended to be higher than those that have relied on behavior observation (e.g., Hay et al., 2011). Because 
parent-report and observational assessments have complementary strengths and weaknesses (e.g., respectively large vs. small samples of behavior and subjective vs. objective rating criteria), it is at present difficult to say what the "truth" of the matter is.

A second limitation was our choice to combine pinching and scratching into a single item. When designing the aggression questionnaire, we reasoned that infant pinching and scratching, because of motor immaturity (e.g., lack of precise targeting), may be difficult for parents to differentiate. Thus, we decided to combine them. However, in retrospect, this decision may have worked against the goals of documenting the development of individual physically aggressive acts. Researchers of such phenomena may wish to separate pinching and scratching into separate items in future research.

A third limitation concerns the participation of half of the study parents in an intervention designed to prevent intimate partner violence. The intervention terminated prior to the 8-month assessment and there were no intervention effects on child aggression, defiance, distress to limitations, or activity level at any age, as reported in Lorber et al. (2014) and Lorber et al., 2015. However, undetected nonlinear effects are possible. For example, the intervention may have impacted child behavior in an unidentified subgroup of the sample.

A fourth limitation concerns the sample composition. The sample was selected to be at moderately increased risk of intimate partner violence, based on at least on parent being 30 years old or younger and on the presence of intimate psychological aggression (e.g., shouting, yelling, insults, or swearing at the partner). Age is modestly inversely associated with family violence (e.g., O’Leary et al., 2007; Slep \& O’Leary, 2007). Moreover, although psychological aggression is reported by nearly all couples (O’Leary et al., 2007), our inclusion criteria eliminated $11 \%$ of couples from consideration based on the absence of this behavior. Thus, the present sample was slightly more aggressive than the population from which they were drawn. Yet the $2 \%$ of couples who reported physical aggression that resulted 
in injuries, pain, or fear also screened out, slightly truncating the high end of interparental aggression. As an additional risk-attenuating inclusion criterion, study parents were required to be married or cohabiting. Single parenthood confers higher risk for child physical aggression (Tremblay et al., 2004). All things considered, it is reasonable to suppose that the present inclusion criteria netted a sample of families whose children had a somewhat elevated risk of aggression. As previously noted, this design feature facilitated the juxtaposition of atypical and normative development. However, it came at the potential price of generalizability. Although the rough similarities of some of the present findings to those of prior studies is encouraging (e.g., Alink et al., 2006; Del Vecchio, 2006; Hay et al., 2010; Nærde et al., 2014), the generalization of the present findings to the broader population of children cannot be safely assumed. Increasing the present study's generalizability, however, the median family income was fairly comparable to that of the US population as was the racial/ethnic composition of the sample (see supplemental Table S1).

A fifth limitation was pointed out by an anonymous reviewer who noted the challenges of reliably measuring physical aggression in infancy and early toddlerhood due to short-term fluctuations in child behavior and parent reporting, perhaps reflecting measurement error. The previously reported composite physical aggression stabilities in the present sample (e.g., mother-father mean stability of .49 from 8 to 15 months and .61 from 15 to 24 months) do not suggest the presence of excessive measurement error. Yet the reviewer's point is well taken in that development is rapid during infancy and toddlerhood and more tightly spaced assessment intervals would be even better suited understanding individual continuity and change in physical aggression in this period.

\section{Conclusions and Implications}

Using a moderate risk sample of parents, the present study provided a detailed examination of the development of physically aggressive behaviors in the first two years of 
life. The results revealed the commonality of physical aggression at all ages studied and the diverging developmental patterns of individual behaviors. We further identified the behavioral pathways of individual physically aggressive behaviors from infancy through toddlerhood and identified a large subset of infants who displayed an increased propensity to aggress at all ages.

As reviewed herein, prior research has shown that a group of children who will exhibit persistently elevated physically aggression for years to come is identifiable by 17 to 24 months of age (e.g., NICHD Early Child Care Research Network \& Arsenio, 2004; Tremblay et al., 2004). Unfortunately, infancy era interventions have shown very limited effects in preventing this highly consequential behavior pattern in early childhood. Even those interventions that have notable positive effects on children's and adolescents' later development (e.g., Olds and colleagues' nurse home visiting program; Olds et al., 1998), have small, nonsignificant, and/or conditional effects on early physical aggression (SidoraArcoleo et al., 2010). A better understanding of the development of physical aggression in the first two years of life will likely be necessary to enhance our ability to prevent persistent early aggression by identifying new age-specific targets for intervention. Our results, in combination with recent British, Dutch, and Norwegian studies, are building blocks toward this goal. Taken together, they suggest that physical aggression is a normative feature of infancy and early toddlerhood, but that it is nonetheless consequential and worthy of additional study toward the betterment of public health. 


\section{References}

Achenbach, T. M., \& Rescorla, L. A. (2000). Manual for the ASEBA pre-school forms and profiles. Burlington, VT: University of Vermont, Department of Psychiatry.

Adolph, K. E., \& Berger, S. E. (2006). Physical and motor development. In M. H. Bornstein \& M. E. Lamb (Eds.), Developmental science: An advanced textbook $\left(5^{\text {th }}\right.$ Ed.; pp. 223-281). Mahwah, NJ: Erlbaum.

Adolph, K. E., \& Robinson, S. R. (2015). Motor development. In L. S. Liben, U. Mueller, \& R. M. Lerner (Eds.), Handbook of child psychology and developmental science, Volume 2, Cognitive processes (pp.113-157). Hoboken, NJ: John Wiley \& Sons, Inc.

Alink, L. R. A., Mesman, J., Van Zeijl, J., Stolk, M. N., Juffer, F., Koot, H. M., ...Van IJzendoorn, M. H. (2006). The early childhood aggression curve: Development of physical aggression in 10 to 50 month-old children. Child Development, 77, 954-966. doi:10.1111/j.1467-8624.2006.00912.x

Beauducel, A., \& Herzberg, P. Y. (2006). On the performance of maximum likelihood versus means and variance adjusted weighted least squares estimation in CFA. Structural Equation Modeling, 13, 186-203. doi:10.1207/s15328007sem1302_2

Benjamini, Y., \& Hochberg, Y. (1995). Controlling the false discovery rate: a practical and powerful approach to multiple testing. Journal of the Royal Statistical Society. Series B (Methodological), 289-300. http://www.jstor.org

Biringen, Z., Emde, R. N., Campos, J. J., \& Appelbaum, M. I. (1995). Affective reorganization in the infant, the mother, and the dyad: The role of upright locomotion and its timing. Child Development, 66, 499-514. doi:10.2307/1131593

Braungart-Rieker, J. M., Hill-Soderlund, A. L., \& Karrass, J. (2010). Fear and anger reactivity trajectories from 4 to 16 months: The roles of temperament, regulation, and maternal sensitivity. Developmental Psychology, 46, 791-804. doi:10.1037/a0019673 
Brownlee, J. R., \& Bakeman, R. (1981). Hitting in toddler-peer interaction. Child Development, 1076-1079. doi:10.2307/1129115

Campbell, S. B., Spieker, S., Burchinal, M., Poe, M. D., \& NICHD Early Child Care Research Network (2006). Trajectories of aggression from toddlerhood to age 9 predict academic and social functioning through age 12. Journal of Child Psychology and Psychiatry, 47, 791-800. doi:10.1111/j.1469-7610.2006.01636.x

Campos, J., Anderson, D., Barbu-Roth, M., Hubbard, E., Hertenstein, M., \& Witherington, D. (2000). Travel broadens the mind. Infancy, 1, 149-219. doi:10.1207/S15327078IN0102_1

Côté, S. M., Vaillancourt, T., Barker, E. D., Nagin, D., \& Tremblay, R. E. (2007). The joint development of physical and indirect aggression: Predictors of continuity and change during childhood. Development and Psychopathology, 19, 37-55. doi:10.10170S0954579407070034

Côté, S., Vaillancourt, T., LeBlanc, J. C., Nagin, D. S., \& Tremblay, R. E. (2006). The development of physical aggression from toddlerhood to pre-adolescence: A nation wide longitudinal study of Canadian children. Journal of Abnormal Child Psychology, 34, 68-82. doi:10.1007/s10802-005-9001-z

Davies, H. T. O., Crombie, I. K., \& Tavakoli, M. (1998). When can odds ratios mislead? British Medical Journal, 316, 989-991. doi:10.1136/bmj.316.7136.989

Del Vecchio, T. (2006). Discipline responses to child aggression: A developmental model and experimental analysis. (Unpublished dissertation). Stony Brook University, Stony Brook New York.

Dodge, K. A., Coie, J. D., \& Lynam, D. (2006). Aggression and antisocial behavior in youth. In W. Damon \& R. M. Lerner (Eds.), Handbook of child psychology, Vol. 3: Social, emotional and personality development (pp. 719-788). Hoboken, NJ: John Wiley \& 
Sons, Inc.

Dunn, J., \& Munn, P. (1985). Becoming a family member: Family conflict and the development of social understanding in the second year. Child Development, 56, 480492. doi:10.2307/1129735

Eckerman, C. O., Whatley, J. L., \& Kutz, S. L. (1975). Growth of social play with peers during the second year of life. Developmental Psychology, 11, 42-49. doi:10.1037/h0076131

Halford, W. K., Petch, J., \& Creedy, D. K. (2010). Promoting a positive transition to parenthood: A randomized clinical trial of couple relationship education. Prevention Science, 11, 89-100. doi:10.1007/s11121-009-0152-y

Hay, D. F. (2005). The beginnings of aggression in infancy. In R. E. Tremblay, W. W. Hartup, \& J. Archer (Eds.), Developmental origins of aggression (pp. 107-132). New York, NY: Guilford Press.

Hay, D. F. (2016). The early development of human aggression. Child Development Perspectives. doi:10.1111/cdep.12220

Hay, D. F., Hurst, S., Waters, C. S., \& Chadwick, A. (2011). Infants' use of force to defend toys: The origins of instrumental aggression. Infancy, 16, 471-489. doi:10.1111/j.1532-7078.2011.00069.x

Hay, D. F., Perra, O., Hudson, K., Waters, C. S., Mundy, L., Phillips, R., ... \& Van Goozen, S. (2010). Identifying early signs of aggression: psychometric properties of the Cardiff infant contentiousness scale. Aggressive Behavior, 36, 351-357. doi:10.1002/ab.20363

Hay, D. F., Waters, C. S., Perra, O., Swift, N., Kairis, V., Phillips, R., ... \& Goozen, S. (2014). Precursors to aggression are evident by 6 months of age. Developmental Science, 17, 471-480. doi:10.1111/desc.12133 
Heyman, R. E., \& Slep, A. M. S. (2006). Creating and field-testing diagnostic criteria for partner and child maltreatment. Journal of Family Psychology, 20, 397-408. doi:10.1037/0893-3200.20.3.397.

Heyman, R. E., Slep, A. M. S., Lorber, M. F., Mitnick, D. M., Xu, S., Baucom, J. W., \& Niolon, P. H. (2017). A Randomized, Controlled Trial of the Impact of the Couple CARE for Parents of Newborns Program on the Prevention of Intimate Partner Violence and Relationship Problems. Unpublished manuscript.

Imai, K., Keele, L., \& Tingley, D. (2010). A general approach to causal mediation analysis. Psychological Methods, 15, 309-334. doi:10.1037/a0020761.

Johnston, C., \& Murray, C. (2003). Incremental validity in the psychological assessment of children and adolescents. Psychological Assessment, 15, 496-507. doi:10.1037/10403590.15 .4 .496

Kerr, D. C., Lunkenheimer, E. S., \& Olson, S. L. (2007). Assessment of child problem behaviors by multiple informants: A longitudinal study from preschool to school entry. Journal of Child Psychology and Psychiatry, 48, 967-975. doi:10.1111/j.14697610.2007.01776.x

Klimes-Dougan, B., \& Kopp, C. B. (1999). Children's conflict tactics with mothers: A longitudinal investigation of the toddler and preschool years. Merrill-Palmer Quarterly, 45, 226-241. Downloaded from http://www.jstor.org/stable/23093676

Lemerise, E. A., \& Dodge, K. A. (2008). The development of anger and hostile interactions. In M. D. Lewis, J. M. Haviland-Jones, \& L. F. Barrett (Eds.), Handbook of emotions (pp. 730-741). New York, NY: Guilford Press.

Lewis, M. D. (2008). The emergence of human emotions. In M. D. Lewis, J. M. HavilandJones, \& L. F. Barrett (Eds.), Handbook of emotions (pp. 304-319). New York: Guilford Press. 
Lorber, M. F., Del Vecchio, T., \& Slep, A. M. S. (2014). Infant externalizing behavior as a self-organizing construct. Developmental Psychology, 50, 1854-1861. doi:10.1037/a0036985

Lorber, M. F., Del Vecchio, T., \& Slep, A. M. S. (2015). The emergence and evolution of infant externalizing behavior. Development and Psychopathology, 27, 663-680. doi:10.1017/S0954579414000923

Lorber, M. F., \& Slep, A. M. S. (2015). Are persistent early onset child conduct problems predicted by the trajectories and initial levels of discipline practices? Developmental Psychology, 51, 1048-1061. doi:10.1037/a0039421

Maccoby, E. E. (1980). Social development: Psychological growth and the parent-child relationship. New York, NY: Harcourt Brace Jovanovich.

MacKinnon, D. P., Lockwood, C. M., Hoffman, J. M., West, S. G., \& Sheets, V. (2002). A comparison of methods to test mediation and other intervening variable effects. Psychological Methods, 7, 83-104. doi:10.1037/1082-989X.7.1.83

Masten, A. S. (2011). Resilience in children threatened by extreme adversity: Frameworks for research, practice, and translational synergy. Development and Psychopathology, 23, 493-506. doi:10.1017/S0954579411000198

Moffitt, T. E. (1993). Adolescence-limited and life-course-persistent antisocial behavior: a developmental taxonomy. Psychological Review, 100, 674- 701. doi:10.1037/0033295X.100.4.674.

Moffitt, T. E. (2005). The new look of behavioral genetics in developmental psychopathology: Gene-environment interplay in antisocial behaviors. Psychological Bulletin, 131, 533-554. doi:10.1037/0033-2909.131.4.533. 
Muthén, B. \& Asparouhov, T. (2015) Causal effects in mediation modeling: An introduction with applications to latent variables, Structural Equation Modeling: A Multidisciplinary Journal, 22, 12-23. doi:10.1080/10705511.2014.935843

Muthén, L.K., \& Muthén, B.O. (1998-2012). Mplus User's Guide. Seventh Edition. Los Angeles, CA: Muthén \& Muthén.

Nærde, A., Ogden, T., Janson, H., \& Zachrisson, H. D. (2014). Normative development of physical aggression from 8 to 26 months. Developmental Psychology, 50, 1710-1720. doi:10.1037/a0036324

NICHD Early Child Care Research Network \& Arsenio, W. F. (2004). Trajectories of physical aggression from toddlerhood to middle childhood: Predictors, correlates, and outcomes. Monographs of the Society for Research in Child Development, 69, 1-129. doi:10.1111/j.0037-976X.2004.00312.x.

Nylund, K. L., Asparouhov, T., \& Muthén, B. O. (2007). Deciding on the number of classes in latent class analysis and growth mixture modeling: A Monte Carlo simulation study. Structural Equation Modeling, 14, 535-569. doi:10.1080/10705510701575396

Olds, D., Henderson Jr, C. R., Cole, R., Eckenrode, J., Kitzman, H., Luckey, D., ... \& Powers, J. (1998). Long-term effects of nurse home visitation on children's criminal and antisocial behavior: 15-year follow-up of a randomized controlled trial. Journal of the American Medical Association, 280, 1238-1244. doi:10.1001/jama.280.14.1238

O'Leary, K. D., Slep, A. M. S., \& O'Leary, S. G. (2007). Multivariate models of men's and women's partner aggression. Journal of Consulting and Clinical Psychology, 75, 752764. doi:10.1037/0022-006X.75.5.752

Patterson, G. R. (1993). Orderly change in a stable world: The antisocial trait as a chimera. Journal of consulting and Clinical Psychology, 61, 911-919. doi:10.1037/0022006X.61.6.911 
Patterson, G. R. (2002). The early development of coercive family process. In J. B. Reid, G. R. Patterson, \& J. E. Snyder (Eds.), Antisocial behavior in children and adolescents: A developmental analysis and model for intervention (pp. 25-44). Washington, DC: American Psychological Association. doi:10.1037/10468-002

Preacher, K. J., \& Kelley, K. (2011). Effect size measures for mediation models: Quantitative strategies for communicating indirect effects. Psychological Methods, 16, 93-115. doi: $10.1037 / \mathrm{a} 0022658$

Shaw, D. S., \& Bell, R. Q. (1993). Developmental theories of parental contributors to antisocial behavior. Journal of Abnormal Child Psychology, 21, 493-518. doi:10.1007/BF00916316

Shaw, D. S., Lacourse, E., \& Nagin, D. S. (2005). Developmental trajectories of conduct problems and hyperactivity from ages 2 to 10. Journal of Child Psychology and Psychiatry, 46, 931-942. doi:10.1111/j.1469-7610.2004.00390.x

Sidora-Arcoleo, K., Anson, E., Lorber, M., Cole, R., Olds, D., \& Kitzman, H. (2010). Differential effects of a nurse home-visiting intervention on physically aggressive behavior in children. Journal of Pediatric Nursing, 25, 35-45.

doi:10.1016/j.pedn.2008.07.011

Slep, A. M. S., \& O'Leary, S. G. (2007). Multivariate models of mothers' and fathers' aggression toward their children. Journal of Consulting and Clinical Psychology, 75, 739-751. doi:10.1037/0022-006X.75.5.739

Sroufe, L. (2009). The concept of development in developmental psychopathology. Child Development Perspectives, 3, 178-183. doi:10.1111/j.1750-8606.2009.00103.x

Sroufe, L. A., Egeland, B., Carlson, E. A., \& Collins, W. A. (2005). The development of the person: The Minnesota Study of Risk and Adaptation from birth to adulthood. New York: Guilford. 
Tomasello, M., Carpenter, M., Call, J., Behne, T., \& Moll, H. (2005). Understanding and sharing intentions: The origins of cultural cognition. Behavioral and Brain Sciences, 28, 675-690. doi:10.1017/S0140525X05380125

Tremblay, R. E. (2000). The development of aggressive behaviour during childhood: What have we learned in the past century? International Journal of Behavioral Development, 24, 129-141. doi:10.1080/016502500383232

Tremblay, R. E., \& Côté, S. (2005). The developmental origins of aggression: Where are we going? In R. E. Tremblay, W. W. Hartup, \& J. Archer (Eds.), Developmental origins of aggression (pp. 447-464). New York, NY: Guilford Press.

Tremblay, R. E., \& Nagin, D. S. (2005). The developmental origins of physical aggression in humans. In R. E. Tremblay, W. W. Hartup, \& J. Archer (Eds.), Developmental origins of aggression (pp. 83-106). New York, NY: Guilford Press.

Tremblay, R. E., Japel, C., Pérusse, D., McDuff, P., Boivin, M., Zoccolillo, M., \& Montplaisir, J. (1999). The search for the age of 'onset' of physical aggression: Rousseau and Bandura revisited. Criminal Behaviour and Mental Health, 9, 8-23. doi: $10.1002 / \mathrm{cbm} .288$

Tremblay, R. E., Nagin, D. S., Séguin, J. R., Zoccolillo, M., Zelazo, P. D., Boivin, M., ... Japel, C. (2004). Physical aggression during early childhood: Trajectories and predictors. Pediatrics, 114, 43-50. doi:10.1542/peds.114.1.e43

U.S. Census Bureau. (2007-2011). 2012 American Community Survey 5-Year Estimates. Retrieved from http://factfinder2.census.gov

Van Zeijl, J., Mesman, J., Stolk, M. N., Alink, L. R., van IJzendoorn, M. H., BakermansKranenburg, M. J., ... Koot, H. M. (2006). Terrible ones? Assessment of externalizing behaviors in infancy with the Child Behavior Checklist. Journal of Child Psychology and Psychiatry, 47, 801-810. doi:10.1111/j.1469-7610.2006.01616.x 
World Health Organization Multicentre Growth Reference Study Group (2006). WHO Motor Development Study: Windows of achievement for six gross motor development milestones. Acta Paediatrica, 95, 86-95. doi:10.1111/j.1651-2227.2006.tb02379.x 
Table 1

Probabilities of Physically Aggressive Behaviors by Age and Latent Class

\begin{tabular}{|c|c|c|c|c|c|c|c|c|c|c|}
\hline \multirow[b]{3}{*}{ Age, Behavior } & \multicolumn{3}{|c|}{$\begin{array}{l}\text { Full Sample } \\
\text { Probabilities }\end{array}$} & \multicolumn{3}{|c|}{$\begin{array}{c}\text { Class 1 } \\
\text { Probabilities }\end{array}$} & \multicolumn{3}{|c|}{$\begin{array}{c}\text { Class } 2 \\
\text { Probabilities }\end{array}$} & \multirow{3}{*}{$\begin{array}{l}\mathrm{C} 1 \\
\text { vs. } \\
\mathrm{C} 2 \\
p^{\mathrm{a}} \\
\end{array}$} \\
\hline & \multirow[b]{2}{*}{ Est. } & \multicolumn{2}{|c|}{$95 \% \mathrm{CI}$} & \multirow[b]{2}{*}{ Est. } & \multicolumn{2}{|c|}{$95 \% \mathrm{CI}$} & \multirow[b]{2}{*}{ Est. } & \multicolumn{2}{|c|}{$95 \% \mathrm{CI}$} & \\
\hline & & Low & High & & Low & High & & Low & High & \\
\hline \multicolumn{11}{|l|}{8 months } \\
\hline Kick & .219 & .163 & .274 & .370 & .259 & .482 & .102 & .041 & .164 & .027 \\
\hline Push & .130 & .085 & .175 & .222 & .127 & .316 & .060 & .016 & .104 & .049 \\
\hline Hit & .386 & .321 & .451 & .575 & .461 & .690 & .241 & .146 & .336 & .020 \\
\hline Bite & .299 & .238 & .360 & .510 & .394 & .626 & .139 & .068 & .211 & .020 \\
\hline Pull hair & .729 & .669 & .789 & .901 & .810 & .992 & .599 & .501 & .696 & .087 \\
\hline Pinch/scratch & .439 & .373 & .506 & .633 & .498 & .768 & .293 & .204 & .381 & .020 \\
\hline \multicolumn{11}{|l|}{15 months } \\
\hline Kick & .179 & .124 & .235 & .371 & .254 & .487 & .046 & -.015 & .108 & .208 \\
\hline Push & .310 & .243 & .377 & .520 & .399 & .641 & .164 & .070 & .257 & .042 \\
\hline Hit & .620 & .549 & .690 & .880 & .801 & .959 & .438 & .311 & .566 & .054 \\
\hline Bite & .459 & .387 & .531 & .791 & .682 & .900 & .226 & .128 & .324 & .036 \\
\hline Pull hair & .503 & .430 & .575 & .747 & .612 & .881 & .332 & .235 & .428 & .036 \\
\hline Pinch/scratch & .437 & .365 & .509 & .695 & .557 & .833 & .256 & .165 & .347 & .036 \\
\hline \multicolumn{11}{|l|}{24 months } \\
\hline Kick & .312 & .252 & .371 & .605 & .487 & .723 & .107 & .036 & .177 & .032 \\
\hline Push & .494 & .429 & .558 & .766 & .670 & .862 & .303 & .202 & .404 & .027 \\
\hline Hit & .668 & .608 & .729 & .953 & .900 & 1.006 & .467 & .356 & .578 & .122 \\
\hline Bite & .316 & .256 & .376 & .631 & .486 & .777 & .095 & .039 & .152 & .032 \\
\hline Pull hair & .307 & .248 & .367 & .644 & .488 & .799 & .072 & .022 & .122 & .062 \\
\hline Pinch/scratch & .316 & .256 & .376 & .553 & .420 & .686 & .150 & .084 & .217 & .027 \\
\hline
\end{tabular}


Table 2

Associations of Physically Aggressive Behaviors Over Time

\begin{tabular}{|c|c|c|c|c|c|c|c|c|c|c|c|c|c|c|c|c|c|}
\hline Age, behavior & 1 & 2 & 3 & 4 & 5 & 6 & 7 & 8 & 9 & 10 & 11 & 12 & 13 & 14 & 15 & 16 & 17 \\
\hline \multicolumn{18}{|l|}{8 months } \\
\hline \multicolumn{18}{|l|}{ 1. Kick } \\
\hline 2. Push & .66 & & & & & & & & & & & & & & & & \\
\hline 3. Hit & .53 & .54 & & & & & & & & & & & & & & & \\
\hline 4. Bite & .30 & .38 & .48 & & & & & & & & & & & & & & \\
\hline 5. Pull hair & .47 & .57 & .66 & .55 & & & & & & & & & & & & & \\
\hline 6. Pinch/scratch & .44 & .42 & .50 & .54 & .69 & & & & & & & & & & & & \\
\hline \multicolumn{18}{|l|}{15 months } \\
\hline 7. Kick & .43 & -.03 & .21 & .37 & .01 & .23 & & & & & & & & & & & \\
\hline 8. Push & .09 & -.07 & .22 & .36 & .13 & .24 & .64 & & & & & & & & & & \\
\hline 9. Hit & .06 & .10 & .29 & .30 & .23 & .18 & .57 & .69 & & & & & & & & & \\
\hline 10. Bite & .28 & .02 & .15 & .20 & .19 & .30 & .30 & .44 & .55 & & & & & & & & \\
\hline 11. Pull hair & .31 & .26 & .35 & .22 & .50 & .26 & .28 & .28 & .44 & .43 & & & & & & & \\
\hline 12. Pinch/scratch & .37 & .19 & .24 & .39 & .09 & .36 & .39 & .16 & .50 & .48 & .69 & & & & & & \\
\hline \multicolumn{18}{|l|}{24 months } \\
\hline 13. Kick & .28 & .21 & .26 & .28 & .34 & .29 & .58 & .50 & .47 & .47 & .42 & .25 & & & & & \\
\hline 14. Push & .20 & .01 & .20 & .11 & .03 & .03 & .34 & .43 & .52 & .42 & .28 & .20 & .54 & & & & \\
\hline 15. Hit & .00 & .23 & .16 & .33 & -.01 & -.02 & .44 & .38 & .56 & .47 & .23 & .33 & .67 & .74 & & & \\
\hline 16. Bite & .34 & .32 & .28 & .19 & .27 & .34 & .16 & .30 & .35 & .67 & .38 & .39 & .47 & .49 & .60 & & \\
\hline 17. Pull hair & .34 & .29 & .24 & .25 & .44 & .42 & .37 & .10 & .30 & .56 & .47 & .43 & .47 & .44 & .63 & .74 & \\
\hline 18. Pinch/scratch & .28 & .33 & .17 & .12 & .24 & .13 & .16 & .20 & .47 & .47 & .38 & .56 & .36 & .26 & .43 & .60 & .60 \\
\hline
\end{tabular}

Note. Coefficients are probit estimates (tetrachoric correlations) from a saturated covariance model; boxed coefficients were statistically evaluated; bolded coefficients were significant after the FDR adjustment was applied to their $p$-values. 
Table 3

Behavioral Pathways of Physically Aggressive Behaviors

\begin{tabular}{|c|c|c|c|c|c|c|c|c|c|c|c|c|c|}
\hline \multirow[b]{2}{*}{ Path } & \multicolumn{4}{|c|}{$\alpha$} & \multicolumn{4}{|c|}{$\beta$} & \multicolumn{5}{|c|}{ Indirect Effect } \\
\hline & $B$ & $S E$ & CI low & CI high & $B$ & $S E$ & CI low & CI high & PNIE & $S E$ & CI low & CI high & $\mathrm{P}_{\mathrm{M}}$ \\
\hline kick $\rightarrow$ hair $\rightarrow$ bite & 0.56 & 0.26 & 0.05 & 1.09 & 0.36 & 0.15 & 0.09 & 0.66 & 0.04 & 0.02 & 0.01 & 0.11 & 0.18 \\
\hline kick $\rightarrow$ pinch $^{\mathrm{a}} \rightarrow$ bite & 0.66 & 0.26 & 0.17 & 1.18 & 0.37 & 0.15 & 0.09 & 0.68 & 0.05 & 0.03 & 0.01 & 0.12 & 0.23 \\
\hline kick $\rightarrow$ kick $\rightarrow$ hair & 0.76 & 0.28 & 0.20 & 1.29 & 0.35 & 0.16 & 0.05 & 0.69 & 0.05 & 0.03 & 0.01 & 0.15 & 0.23 \\
\hline kick $\rightarrow$ hair $\rightarrow$ hair & 0.56 & 0.26 & 0.05 & 1.09 & 0.49 & 0.16 & 0.19 & 0.84 & 0.05 & 0.03 & 0.01 & 0.12 & 0.24 \\
\hline kick $\rightarrow$ pinch $\rightarrow$ hair & 0.66 & 0.26 & 0.17 & 1.18 & 0.42 & 0.16 & 0.14 & 0.75 & 0.06 & 0.03 & 0.02 & 0.13 & 0.26 \\
\hline bite $\rightarrow$ kick $\rightarrow$ hit & 0.63 & 0.25 & 0.13 & 1.11 & 0.44 & 0.21 & 0.11 & 0.91 & 0.05 & 0.02 & 0.01 & 0.11 & 0.25 \\
\hline bite $\rightarrow$ push $\rightarrow$ hit & 0.61 & 0.23 & 0.18 & 1.07 & 0.35 & 0.16 & 0.07 & 0.69 & 0.05 & 0.03 & 0.01 & 0.11 & 0.25 \\
\hline bite $\rightarrow$ hit $\rightarrow$ hit & 0.51 & 0.23 & 0.07 & 0.99 & 0.64 & 0.18 & 0.32 & 1.01 & 0.07 & 0.03 & 0.01 & 0.13 & 0.34 \\
\hline bite $\rightarrow$ pinch $\rightarrow$ hit & 0.68 & 0.22 & 0.25 & 1.12 & 0.29 & 0.15 & 0.02 & 0.59 & 0.05 & 0.03 & 0.01 & 0.11 & 0.25 \\
\hline hair $\rightarrow$ hair $\rightarrow$ kick & 0.90 & 0.25 & 0.44 & 1.41 & 0.38 & 0.16 & 0.10 & 0.72 & 0.06 & 0.03 & 0.02 & 0.16 & 0.30 \\
\hline hair $\rightarrow$ hair $\rightarrow$ hair & 0.90 & 0.25 & 0.43 & 1.40 & 0.43 & 0.17 & 0.11 & 0.79 & 0.06 & 0.03 & 0.02 & 0.15 & 0.22 \\
\hline pinch $\rightarrow$ bite $\rightarrow$ kick & 0.49 & 0.21 & 0.08 & 0.89 & 0.49 & 0.16 & 0.21 & 0.83 & 0.05 & 0.02 & 0.01 & 0.11 & 0.27 \\
\hline pinch $\rightarrow$ bite $\rightarrow$ bite & 0.49 & 0.21 & 0.08 & 0.89 & 0.86 & 0.22 & 0.51 & 1.35 & 0.07 & 0.03 & 0.02 & 0.15 & 0.34 \\
\hline pinch $\rightarrow$ pinch $\rightarrow$ bite & 0.60 & 0.21 & 0.19 & 1.02 & 0.35 & 0.15 & 0.07 & 0.66 & 0.04 & 0.02 & 0.01 & 0.10 & 0.20 \\
\hline pinch $\rightarrow$ bite $\rightarrow$ hair & 0.49 & 0.21 & 0.08 & 0.89 & 0.61 & 0.18 & 0.30 & 1.01 & 0.05 & 0.03 & 0.01 & 0.12 & 0.20 \\
\hline pinch $\rightarrow$ pinch $\rightarrow$ hair & 0.60 & 0.21 & 0.19 & 1.02 & 0.40 & 0.16 & 0.11 & 0.73 & 0.04 & 0.02 & 0.01 & 0.11 & 0.18 \\
\hline
\end{tabular}

Note. $\mathrm{PNIE}=$ pure natural indirect effect; $\mathrm{P}_{\mathrm{M}}=$ ratio of the indirect to total effect; $\alpha=$ path from 8 -mo predictor to 15 -mo mediator; $\beta=$ path

from 15-mo mediator to 24-mo outcome; $\mathrm{CI}=95 \%$ confidence interval; parameters are bootstrapped; ${ }^{\text {a }}$ pinch is shorthand for pinch or scratch. 

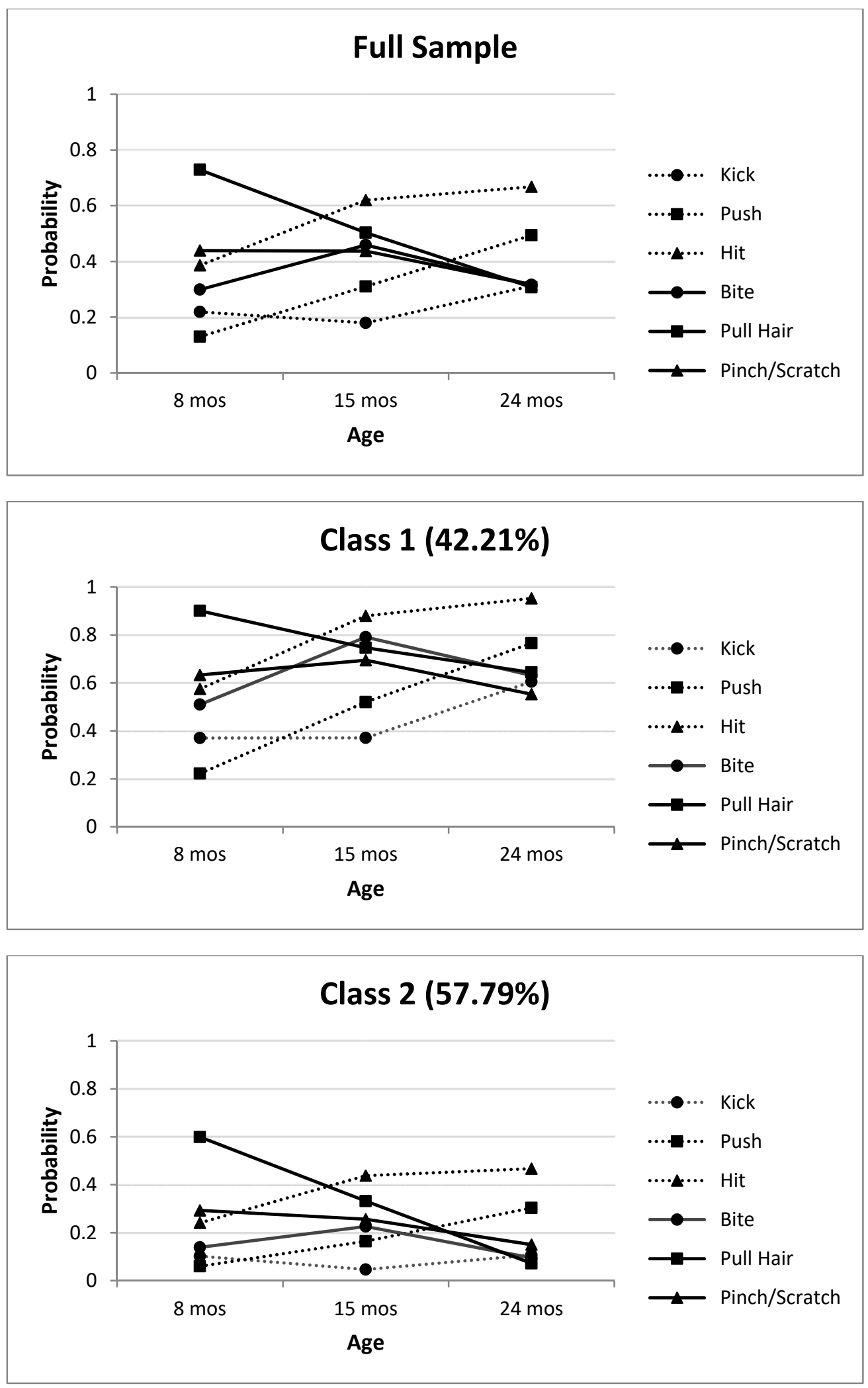

Figure 1. Probabilities of physically aggressive behaviors by age and latent class. 


\section{Online Supplement to The Development of Individual Physically Aggressive Behaviors from Infancy to Toddlerhood}

\section{Recruitment for Randomized Trial}

Research assistants visited the maternity wards of two large suburban hospitals. They approached each new mother to ascertain interest in completing a screening interview for potential inclusion in research on the Couple CARE for Parents program. Upon verbal consent, the research assistant administered a screening interview consisting of demographic questions (e.g., age; marital and cohabitation status), as well questions tapping psychological and physical intimate partner aggression in the entire history of the couple's relationship. The eight psychological aggression items reflected the perpetration and victimization by one of four acts of intimate psychological aggression in the history of their relationship. The remaining questions measured the person's experience of six consequences of partner aggression (e.g., injury, pain, and fear); these are markers of clinically significant intimate partner violence ${ }^{1}$. Upon qualification and a verbal indication of interest in learning more about the study, potential participants were contacted by telephone to learn more details about the study and to schedule a home assessment prior to their child's 3-month birthday.

\section{Routines for Home Visits and Data Collection}

Home visits were scheduled at participating couples' convenience. At each home visit, a research assistant administered the Infant Externalizing Questionnaire, as well as study questionnaires and observational assessments that are not of present focus. The parents typically completed study questionnaires in the same room, commonly a living or dining room. They were instructed to complete the questionnaires independently and specifically asked not to discuss their answers with one another during the home visit. The research assistant was present for the entire home visit and could thus monitor and enforce the independence of questionnaire completion.

\section{Study vs. National and County Demographics}

Table S1

Study vs. National and County Demographics

\begin{tabular}{|c|c|c|c|c|}
\hline & Study Mothers & Study Fathers & US & $\begin{array}{l}\text { County of } \\
\text { Residence }\end{array}$ \\
\hline Latino & $17.80 \%$ & $24.80 \%$ & $16.90 \%$ & $16.50 \%$ \\
\hline \multicolumn{5}{|l|}{ Non-Latino } \\
\hline White & $61.10 \%$ & $52.20 \%$ & $62.80 \%$ & $71.60 \%$ \\
\hline Black or African American ${ }^{a}$ & $14.40 \%$ & $17.40 \%$ & $12.30 \%$ & $7.00 \%$ \\
\hline American Indian and Alaska Native & $0.00 \%$ & $1.10 \%$ & $0.70 \%$ & $0.10 \%$ \\
\hline Asian & $4.40 \%$ & $2.60 \%$ & $4.90 \%$ & $3.50 \%$ \\
\hline Native Hawaiian and Other Pacific Islander & $0.00 \%$ & $0.40 \%$ & $0.20 \%$ & $0.00 \%$ \\
\hline Some other race & $0.00 \%$ & $0.00 \%$ & $0.20 \%$ & $0.20 \%$ \\
\hline Two or more races & $2.20 \%$ & $1.50 \%$ & $2.10 \%$ & $1.20 \%$ \\
\hline College degree ${ }^{b}$ & $40 \%$ & $34 \%$ & $26 \%$ & $30 \%$ \\
\hline Family income & \multicolumn{2}{|c|}{$\$ 56,000$} & $\$ 64,585$ & $\$ 100,179$ \\
\hline
\end{tabular}

Note. US and county statistics are drawn from the 2012 American Community Survey (ACS) ${ }^{2}$, tables DP05, S1901, and S1501; a denotes the ACS "Black or African American" category is approximated by the study

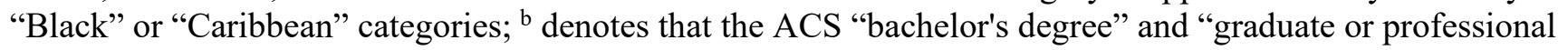
degree" are approximated by the study "college graduate," "some graduate school," and "graduate degree received" categories.

\footnotetext{
${ }^{1}$ Heyman, R. E., \& Slep, A. M. S. (2006). Creating and field-testing diagnostic criteria for partner and child maltreatment. Journal of Family Psychology, 20, 397-408. doi: 10.1037/0893-3200.20.3.397.

2 U.S. Census Bureau. (2007-2011). 2012 American Community Survey 5-Year Estimates. Retrieved from http://factfinder2.census.gov
} 


\section{Table S2}

\section{Online Supplement to The Development of Individual Physically Aggressive Behaviors from Infancy to Toddlerhood}

\section{Associations of Physically Aggressive Behaviors Over Time}

\begin{tabular}{|c|c|c|c|c|c|c|c|c|c|c|c|c|}
\hline \multirow[b]{3}{*}{ Association } & \multicolumn{4}{|c|}{8 to 15 Months } & \multicolumn{4}{|c|}{15 to 24 Months } & \multicolumn{4}{|c|}{8 to 24 Months } \\
\hline & \multirow[b]{2}{*}{ Est. } & \multicolumn{2}{|c|}{$95 \% \mathrm{CI}$} & \multirow[b]{2}{*}{$p^{\mathrm{a}}$} & \multirow[b]{2}{*}{ Est. } & \multicolumn{2}{|c|}{$95 \% \mathrm{CI}$} & \multirow[b]{2}{*}{$p^{\mathrm{a}}$} & \multirow[b]{2}{*}{ Est. } & \multicolumn{2}{|c|}{$95 \% \mathrm{CI}$} & \multirow[b]{2}{*}{$p^{\mathrm{a}}$} \\
\hline & & Low & High & & & Low & High & & & Low & High & \\
\hline \multicolumn{13}{|l|}{ Kick with future } \\
\hline Kick & .43 & .16 & .69 & .012 & .58 & .37 & .79 & .000 & .28 & .02 & .53 & .054 \\
\hline Push & .09 & -.20 & .37 & .650 & .34 & .08 & .60 & .015 & .20 & -.07 & .46 & .168 \\
\hline Hit & .06 & -.22 & .34 & .682 & .44 & .19 & .70 & .003 & .00 & -.28 & .27 & .988 \\
\hline Bite & .28 & .01 & .54 & .058 & .16 & -.11 & .44 & .256 & .34 & .09 & .58 & .024 \\
\hline Pull Hair & .31 & .06 & .57 & .034 & .37 & .12 & .63 & .008 & .34 & .09 & .59 & .024 \\
\hline Pinch/Scratch & .37 & .12 & .62 & .012 & .16 & -.12 & .44 & .256 & .28 & .02 & .54 & .054 \\
\hline \multicolumn{13}{|l|}{ Push with future } \\
\hline Kick & -.03 & -.42 & .35 & .891 & .50 & .29 & .71 & .000 & .21 & -.11 & .52 & .234 \\
\hline Push & -.07 & -.41 & .27 & .891 & .43 & .21 & .64 & .000 & .01 & -.31 & .32 & .968 \\
\hline Hit & .10 & -.23 & .43 & .891 & .38 & .15 & .61 & .002 & .23 & -.10 & .55 & .234 \\
\hline Bite & .02 & -.30 & .35 & .891 & .30 & .06 & .54 & .020 & .32 & .03 & .62 & .093 \\
\hline Pull Hair & .26 & -.05 & .58 & .606 & .10 & -.16 & .35 & .471 & .29 & -.01 & .59 & .116 \\
\hline Pinch/Scratch & .19 & -.13 & .51 & .747 & .20 & -.05 & .45 & .137 & .33 & .03 & .63 & .093 \\
\hline \multicolumn{13}{|l|}{ Hit with future } \\
\hline Kick & .21 & -.06 & .49 & .154 & .47 & .25 & .69 & .000 & .26 & .03 & .49 & .084 \\
\hline Push & .22 & -.03 & .47 & .122 & .52 & .33 & .71 & .000 & .20 & -.03 & .43 & .135 \\
\hline Hit & .29 & .05 & .52 & .051 & .56 & .38 & .75 & .000 & .16 & -.08 & .40 & .198 \\
\hline Bite & .15 & -.09 & .39 & .225 & .35 & .13 & .58 & .002 & .28 & .06 & .51 & .078 \\
\hline Pull Hair & .35 & .13 & .58 & .012 & .30 & .06 & .54 & .014 & .24 & .00 & .47 & .092 \\
\hline Pinch/Scratch & .24 & .00 & .47 & .100 & .47 & .25 & .69 & .000 & .17 & -.07 & .41 & .198 \\
\hline \multicolumn{13}{|l|}{ Bite with future } \\
\hline Kick & .37 & .11 & .63 & .010 & .47 & .26 & .68 & .000 & .28 & .04 & .51 & .063 \\
\hline Push & .36 & .12 & .60 & .009 & .42 & .22 & .63 & .000 & .11 & -.13 & .36 & .361 \\
\hline Hit & .30 & .06 & .54 & .024 & .47 & .27 & .68 & .000 & .33 & .09 & .56 & .042 \\
\hline Bite & .20 & -.04 & .45 & .106 & .67 & .52 & .83 & .000 & .19 & -.05 & .43 & .171 \\
\hline Pull Hair & .22 & -.03 & .46 & .097 & .56 & .36 & .75 & .000 & .25 & .01 & .49 & .080 \\
\hline Pinch/Scratch & .39 & .17 & .62 & .006 & .47 & .26 & .68 & .000 & .12 & -.13 & .37 & .361 \\
\hline
\end{tabular}


Online Supplement to The Development of Individual Physically Aggressive Behaviors from Infancy to Toddlerhood Pull Hair with future

\begin{tabular}{lcccccccccccc} 
Kick & .01 & -.30 & .32 & .952 & .42 & .20 & .64 & .000 & .34 & .10 & .59 & .018 \\
Push & .13 & -.15 & .41 & .531 & .28 & .05 & .50 & .019 & .03 & -.22 & .29 & .964 \\
Hit & .23 & -.03 & .49 & .258 & .23 & -.01 & .46 & .058 & -.01 & -.27 & .26 & .964 \\
Bite & .19 & -.07 & .45 & .320 & .38 & .16 & .60 & .002 & .27 & .02 & .52 & .068 \\
Pull Hair & .50 & .28 & .73 & .000 & .47 & .26 & .68 & .000 & .44 & .21 & .68 & .000 \\
Pinch/Scratch & .09 & -.19 & .36 & .646 & .38 & .15 & .60 & .002 & .24 & -.02 & .51 & .104 \\
Pinch/Scratch with future & & & & & & & & & \\
Kick & .23 & -.05 & .50 & .122 & .25 & .01 & .49 & .050 & .29 & .06 & .51 & .024 \\
Push & .24 & -.01 & .48 & .088 & .20 & -.04 & .43 & .099 & .03 & -.20 & .27 & .847 \\
Hit & .18 & -.06 & .42 & .135 & .33 & .11 & .56 & .006 & -.02 & -.26 & .22 & .847 \\
Bite & .30 & .07 & .53 & .033 & .39 & .17 & .60 & .002 & .34 & .13 & .56 & .006 \\
Pull Hair & .26 & .03 & .49 & .056 & .43 & .21 & .64 & .000 & .42 & .21 & .63 & .000 \\
Pinch/Scratch & .36 & .14 & .58 & .006 & .56 & .37 & .75 & .000 & .13 & -.11 & .37 & .432 \\
\hline
\end{tabular}

Note. Coefficients are probit estimates (tetrachoric correlations) from a saturated covariance model; $p^{\text {a }}$ denotes FDR adjusted $p$-value. 